\title{
Electric Submersible Pump Grounding
}

\author{
Thomas R. Brinner, Member, IEEE, Jeremy D. Atkins, and Marcus O. Durham, Fellow, IEEE
}

\begin{abstract}
Although electric submersible pumps (ESPs) have been produced for almost 100 years, the actual causes of certain electrical failures are still unknown. Why do failures occur on startup or two weeks after an electrical storm? Most of the answers to these questions can be found from an analysis of traditional grounding techniques and consideration of how electrical insulation fails. ESPs are predominantly operated on ungrounded power, which can lead to arcing faults and residual charge. Frequently the wellhead is not even used as a ground. At other times cathodic protection installers insist on no other connections to the wellhead. Some ground wire connections can actually exacerbate the electrical damage done by lightning. Three-wire power systems are still quite prevalent in the oil field. Ferroresonance and lack of third-harmonic magnetizing current can produce very distorted waveforms. All these topic are investigated. A consensus seems to be building that one grounding configuration does provide superior reliability.
\end{abstract}

Index Terms-Cathodic protection, electric submersible pumps (ESPs), ferroresonance, ground resistance, ground wire inductance, grounding, grounding connections, lightning protection, power distribution systems, surge protection, transient voltage surge suppressors (TVSSs), wellhead grounding.

\section{INTRODUCTION}

A $\mathrm{S}$ the production of crude oil in the United States is increasingly assumed by low-overhead independent oil companies, the responsible petroleum engineers are obligated to raise production and keep expenses down. One expense is the cost of lifting or pumping crude out of the ground. When the production method chosen necessitates either high head or flow rate, the electric submersible pump (ESP) can be a viable alternative. However, many factors figure into this lifting choice, and the petroleum engineer has other options over wide ranges of head and flow, most notably the rod pump.

Failures necessitating equipment replacement are the most important factor in the type of artificial lift ultimately chosen. Rod pumps are less reliable than ESPs, but rig and workover costs are much less. Added to this is the significantly lower expense of totally replacing the downhole equipment. Replacement of a failed ESP can easily run from $\$ 15000$ to $\$ 40000$. When more expensive rig costs are added, replacement of a failed ESP becomes a major expense.

Paper PID-04-11, presented at the 2003 IEEE Petroleum and Chemical Industry Technical Conference, Houston, TX, September 15-17, and approved for publication in the IEEE TRANSACTIONS ON INDUSTRY APPLICATIONS by the Petroleum and Chemical Industry Committee of the IEEE Industry Applications Society. Manuscript submitted for review September 18, 2003 and released for publication June 23, 2004.

T. R. Brinner is with PM\&D Engineering, Inc., Broken Arrow, OK 74013 USA (e-mail: pmdeng@onlyinternet.net).

J. D. Atkins is with Deans, Inc., Artesia, NM 88210 USA (e-mail: jdatkins@ deansinc.com).

M. O. Durham is with THEWAY Corporation, Tulsa, OK 74153 USA (e-mail: mod@utulsa.edu).

Digital Object Identifier 10.1109/TIA.2004.834033
Causes of ESP failures are quite varied. Well conditions such as corrosion, abrasion and gas locking contribute to many failures. However, the failure mechanism most feared by petroleum engineers is lightning damage, during or after a storm. In many cases switching surges on the power system can have a similar effect, but being of much lower magnitude, the cause and effect relationship is less obvious. Both conditions could be minimized by adequate suppression of transient voltages on the power supply, and several attempts at this have been made over the years.

In the early 1980s the two major ESP manufacturers introduced lightning filters to protect their equipment [1]. These consisted of series inductors in each phase, surge capacitors protected by surge suppressors at the motor terminals and lightning arresters on the supply side. It was recommended that the lightning arrester should be connected to a high-current or low-resistance ground and the surge capacitors to a low-current ground. When properly applied the lightning filter was an elegant and successful engineering solution to the lightning problem.

Commercial success was never achieved. Electricians installing the filter would not believe that separate grounds could be safe. The requirement to measure ground resistances was time consuming and, once done, confusing as to which ground should be connected where. Finally, the lightning filter was expensive, and when the price of oil crashed in 1986, the product was doomed.

Later, the three-phase transient voltage surge suppressor (TVSS) was introduced into the ESP market. It was less expensive than the filter, but it also afforded less protection to the ESP, primarily because the grounding issues were not properly addressed. This latter fact also led to some TVSS catastrophic failures. Unlike the lightning filter, which actually slows the rate of rise of voltage, the TVSS has to be connected as close to the equipment being protected as possible for maximum effectiveness. However, connections directly across the ESP motor terminals are impossible in a deep well. Consequently grounds and ground wire connections are more important in a TVSS application than they were with the lightning filter.

In an ESP system, an induction motor is operated at the end of an extremely long power cable. Traditional engineering analysis techniques break such an analysis into two cases, wavelengths much greater than the cable length and wavelengths comparable to or shorter than the cable length. These correspond to the power frequency and transient voltage cases, respectively.

At power frequencies, a lumped parameter circuit is used to represent the cable. Conductor resistance is much larger than inductive reactance in the cable, and the reactance can be safely ignored. The transformer equivalent is predominantly leakage inductance. These two components must be added to the winding resistance in the induction motor equivalent circuit to calculate total performance. 
For transient voltages, the cable must be represented by characteristic impedance. Load and source impedances are related to the impedance by reflection coefficients. Since the motor is inductive at wavelengths equivalent to transient voltages, the reactance is much greater than the characteristic impedance, and the reflection coefficient is nearly +1 . This implies that a transient voltage will double in magnitude at the motor terminals, a phenomenon which explains the preponderance of motor and motor lead cable insulation failures.

With 50 - or $60-\mathrm{Hz}$ sine-wave power or variable-frequency and variable-voltage power from a drive, the lumped parameter model is normally sufficient. Power is supplied line-to-line, and microprocessor based motor controllers protect against most power system anomalies. Over loads are usually sand or heavy fluids through the pump, binding in the pump or a three-phase sag in the applied voltage. Voltage swells typically produce a minor overload. Power system parameters that are monitored include loss-of-phase, single-phase, momentary power outage and phase reversal. Reclosers in the power system should have long dropout times to allow opening of the main contactor so that shaft breakage can be avoided. Modern controllers provide accurate and repeatable monitoring over a wide range of temperatures and are far superior to the older analog or electromechanical controls.

When power is supplied from a drive, controller functions are included right in the drive. Unlike other industries the six-step drive has not been displaced by pulsewdith-modulation (PWM) drives. Harmonics out of a drive are sometimes of high-enough frequency, short-enough wavelength, to excite the series resonance of the ESP load [2]. The input impedance of a lossless open-ended cable is given by

$$
Z_{\text {in }}=-j Z_{o} \cot \left(\frac{2 \pi \mathrm{x}}{\lambda}\right) \Omega
$$

where

$\lambda \quad$ wavelength $=\mathrm{c} /\left(\mathrm{f} \sqrt{ } \varepsilon_{\mathrm{r}}\right) \mathrm{m} ;$

$c$ free-space speed of light $=3 \times 10^{8} \mathrm{~m} / \mathrm{s}$;

$\varepsilon_{\mathrm{r}} \quad$ relative permittivity of cable insulation;

$f$ frequency $(\mathrm{Hz})$;

$Z_{o}$ characteristic impedance $(\Omega)$, and $j=\sqrt{ }-1$.

$Z_{\text {in }}$ is impedance that varies with frequency and is initially capacitive. At resonance, the capacitive reactance of the cable equals the inductive reactance of the step-up transformer. Because of the rich harmonic output of the drive, it is not difficult to excite this resonance. Only recently have adequate low-pass filters been installed on drive outputs to convert the common PWM waveform into near perfect sine waves. By so doing the resonance is never excited.

Although equipment grounding, i.e., grounding of metal enclosures and all exposed metal parts, has never been an issue for obvious safety reasons, system grounding has been a hotly debated issue. General industry, in theory if not in practice, condones and embraces the high-resistance ground. High-resistance grounding is the best for:

- immunity to transient overvoltages;

- equipment protection against arcing;

- maintenance cost;
- continued production after first ground fault;

- ease of locating first ground fault;

- ability to coordinate protective devices;

- addition of ground fault protection;

- reducing the frequency of faults;

- potential flashover to ground.

Low-resistance grounding dissipates far more heat and can incur some equipment damage. Therefore, it is somewhat less desirable than the high-resistance ground.

Solid grounding does out perform the other grounding methods with regard to minimizing voltage stress under line-to-ground fault conditions. However, the fault current can be extremely large and cause extensive damage.

In a solidly grounded ESP system it was demonstrated some years ago that current unbalance at the surface is not equal to the current unbalance at the ESP terminals [3]. Expressed differently, currents measured at the surface are not equal to currents entering the motor. This is true because ground fault paths from each of the three phases have different impedances. It is also quite difficult to know just what path ground currents will take.

Ungrounded or floating power is the norm for almost all ESP systems. Obviously there is almost no current associated with the first fault, and because two faults are required before total failure occurs, some reason that this is the best ground connection for a continuous process, like oil production. However, the first ground fault with a high-resistance ground causes no damage either, and the current is large enough to activate protection devices. In all the categories listed above ungrounded power systems perform the worst.

It is surmised that this practice started as the result of a catastrophic event many years ago. That event may have been the ignition of a well fire, and as crude oil and natural gas are highly flammable, only a minor spark is needed for ignition. With solidly grounded power and a short to ground near the motor neutral point a hole could be easily burned completely through the motor housing. With ungrounded power, the housing is never in the circuit, and when two phases short together, arcing is totally contained until protective circuits remove power.

Unfortunately ungrounded power is susceptible to arcing faults, as documented many years ago when multiple motor failures were observed in a factory [4]. The observation was that a high dc voltage remained on the power system and the motors, and this voltage plus the superimposed ac starting voltage was frequently enough to puncture the insulation. dc voltages have been measured on ESP components with power removed.

Why high-resistance grounds have not found acceptance in ESP operations is uncertain. They are an added expense and no guidelines have ever been established as to where or how they should be connected. Also, a small amount of energy is consumed, which is somewhat disconcerting to people paying thousands of dollars each month on electricity bills. Since the ESP will continue to run with one phase grounded, ground faults have not been a major concern. The major downsides with ungrounded power have been the susceptibility to lightning damage and generally poor reliability. 
One alternative to the high-resistance ground is the TVSS. At normal operating voltages, very little power is consumed. An added advantage is the limiting of transient voltages that can result in insulation damage. In fact, the main component in any TVSS is a resistor, a metal (zinc) oxide nonlinear variable resistor or varistor, hence, the name MOV.

Zinc oxide is also the major component in all modern lightning arresters, but for the best transient voltage protection, the design of both ESP and distribution systems must be evaluated. This necessarily has to involve considerations of what is ground, how ground wires should be connected, transient behavior of power transformers, and distribution system construction. The questions of cathodic protection and ferroresonance also need to be addressed.

Insulation failures are generally conceded to occur through a process involving partial discharge and tree growth [5]. Partial discharge is arcing in a small void or imperfection in the insulation due to excessive voltage stress. A byproduct of this is carbonization within the insulation at the point of discharge. This carbon adds to a water or electrical tree that evolved from previous partial discharges. From this theory it is possible to explain failures at startup, failures two to three weeks after a lightning storm, the seemingly fixed number of ESP starts and why dc hipot tests have no relationship to remaining insulation life.

\section{GROUNDS AND THE WELLHEAD}

In power system parlance a ground is simply an electrical connection into the earth. The quality of a ground is determined from a ground resistance measurement where a lower resistance is always better. How such a measurement is made was codified by F. Wenner in 1915 [6]. The most common instrument designed to do this is the three-point ground resistance meter. The three points are the structure under test, the current injection rod and the voltage measurement rod. Obviously inductive and capacitive components are not involved. Recently a new product resembling a clamp-on ammeter has been introduced, which measures the resistance in a loop. For this ground resistance meter to be accurate one end of that loop must be a low-resistance ground or reference point.

Typical grounds are:

- ground rods;

- ground grids;

- chemical grounds;

- power pole butt wraps and plates.

The ground rod is nothing more than an 8-12-ft copper-plated steel rod pounded into the earth. The ground grid consists of multiple ground rods connected together with wires. Minimum spacing between rods should be no less that 2.2 times the rod length [7]. Ground grids are extensively used under power substations and wires are connected to rods using the exothermal weld process discussed later.

Chemical grounds involve perforated pipe filled with some type of salt. The pipe is buried in the ground, and the salt is kept wet. In the process, the salt leaches through the perforations into the surrounding soil and produces a low-resistance ground. Maintenance is required to replenish the salt and to keep it moist.

In power distribution systems every power pole should be equipped with a wire that runs from the top of the pole to the buried bottom. This wire is typically \#6 AWG bare, copper. At the pole bottom or butt the wire is either spirally wrapped or connected to a copper plate. These are referred to as the butt wrap or butt plate. The main purpose of this wire is to minimize pole splitting due to lightning.

During World War II, H. G. Ufer was given the task of protecting the munitions stored in Arizona against the potentially devastating effects of lightning. His grounding solution [8] was to encase copper ground wire inside concrete poured in trenches surrounding the storage buildings. This greatly reduced the ground resistance, because concrete is alkaline, contains moisture and is conductive thereby increasing the surface contacting the soil. Extensions of Ufer's work are now the preferred grounding method used for all commercial buildings.

At a well site the well casing itself is a Ufer ground, because it is cemented in place to prevent any possible ground water contamination. Cementing usually extends 1000 -ft into the ground, but in any case, it must be to at least $100 \mathrm{ft}$ below any treatable water. More recent studies have demonstrated that deep earth grounding [9] further reduces ground resistances. Since a well casing incorporates both features, its ground resistance is very low, and the authors have never measured a wellhead ground resistance over one ohm.

Fagan and Lee performed scientific tests [10] with simple ground rods embedded in concrete. They measured ground resistance and subjected the encased rods to simulated lightning pulses. The results clearly demonstrated that the Ufer ground concept was both workable and reliable when applied to the reinforcing bars in the concrete footers and columns of buildings. The following formula was used for the calculation of ground resistance for a ground rod encased in concrete:

$$
R=\frac{\left(\rho_{o}\left(\ln r_{1}-\ln r_{o}\right)+\rho_{1}\left(\ln 4 L-1-\ln r_{1}\right)\right)}{2 \pi L}
$$

where

$L$ rod length in $\mathrm{cm}$;

$r_{1}$ radius of concrete in $\mathrm{cm}$;

$r_{o}$ radius of rod in $\mathrm{cm}$;

$\rho_{1}$ resistivity of earth in $\Omega \cdot \mathrm{cm}$;

$\rho_{\mathrm{o}}$ resistivity of concrete in $\Omega \cdot \mathrm{cm}$.

Oil well casings range from 5.5- to 8.625-in outside diameter. The largest diameter or surface casing is at the top of the well. Casing thicknesses range from 0.304 to 0.352 in with an average of 0.317. Cementing ranges from 1 to 2 in thick.

For calculation purposes, an 8.625-in outside diameter was assumed for the surface casing, and the surrounding cement was taken to be 1.5 in thick. Ground resistance calculations (2) were made for various values of concrete and soil resistivity and for casings 1000 and $100 \mathrm{ft}$ deep, Figs. 1 and 2, respectively. An uncemented bare casing was included as a reference.

Calculated ground resistances are much lower than those reported by Fagan and Lee for single ground rods. Casings have a large diameter and are much longer than any rod. Unlike their results, the cemented casings did not have lower resistances than the uncemented casing at high soil resistivities. This again was attributed to the greater length and diameter of the casing compared to a typical rod. 


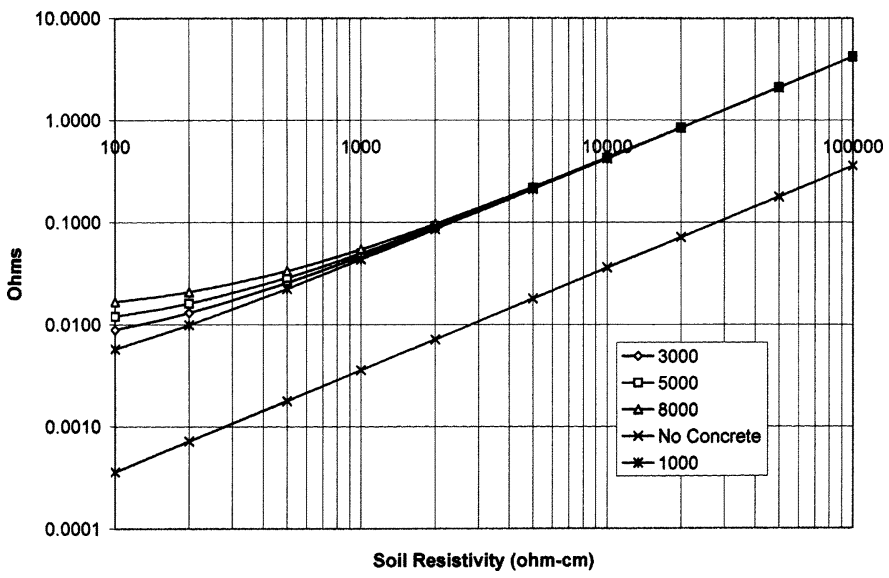

Fig. 1. Wellhead ground resistance $(\Omega)$ of a cemented 1000 -ft surface casing for four values of concrete resistivity $(\Omega \cdot \mathrm{cm})$ and with no concrete.

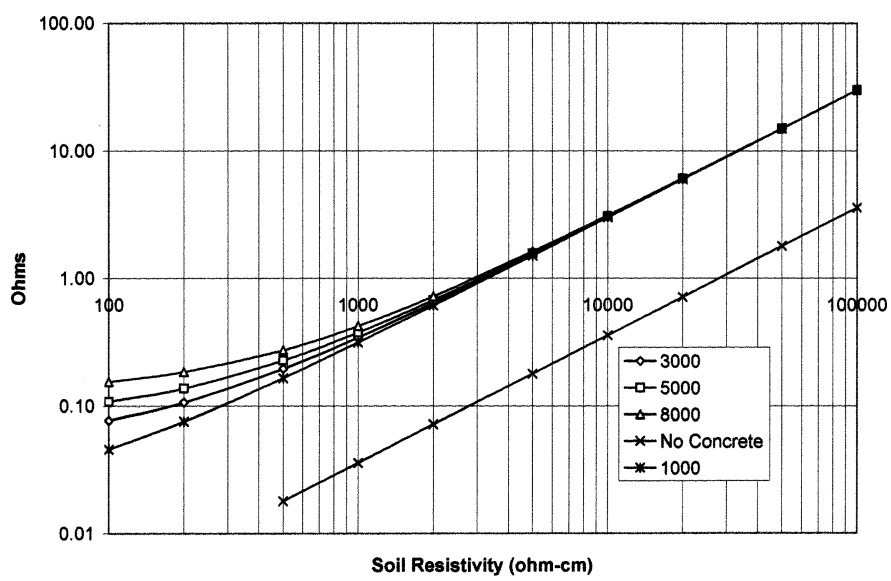

Fig. 2. Wellhead ground resistance $(\Omega)$ of a cemented 100 -ft casing for four values of concrete resistivity $(\Omega \cdot \mathrm{cm})$ and with no concrete.

Assuming constant and uniform soil and concrete resistivities for an oil well, which passes through aquifers, bedrock, clay, loam, sand, etc., is at best a wild approximation. When passing through an aquifer with abundant moisture both resistivities should be significantly lower. Accordingly, a curve was included in Figs. 1 and 2 that had $1000-\Omega \cdot \mathrm{cm}$ concrete resistivity. Although the actual ground resistance would be lower than in Figs. 1 and 2, most ground resistance meters are incapable of measuring these small differences.

Some skeptics believe that the energy associated with a lightning stroke can and will destroy the cement around the well casing. Fagan and Lee also addressed this problem by performing lightning simulation tests on concrete encased ground rods and by calculation. The minor cracks, which occurred in the concrete they tested, could not be related to the simulation pulse. They were attributed to concrete shrinkage.

The calculation performed used a specific heat of $.21 \mathrm{cal} / \mathrm{g}$ for the concrete and assumed just a 1/8-in-thick concrete coating around the rod. It was reasoned that the heating taking place would be greatest closest to the rod. A temperature range from $20^{\circ} \mathrm{C}$ to $100^{\circ} \mathrm{C}$ was used to be close to common earth temperatures and avoid the boiling point of water, respectively. The concrete was assumed to be $5 \%$ water by weight and have a density of $2.1 \mathrm{~g} / \mathrm{cm}^{3}$. Concrete resistivity would vary appreciably over

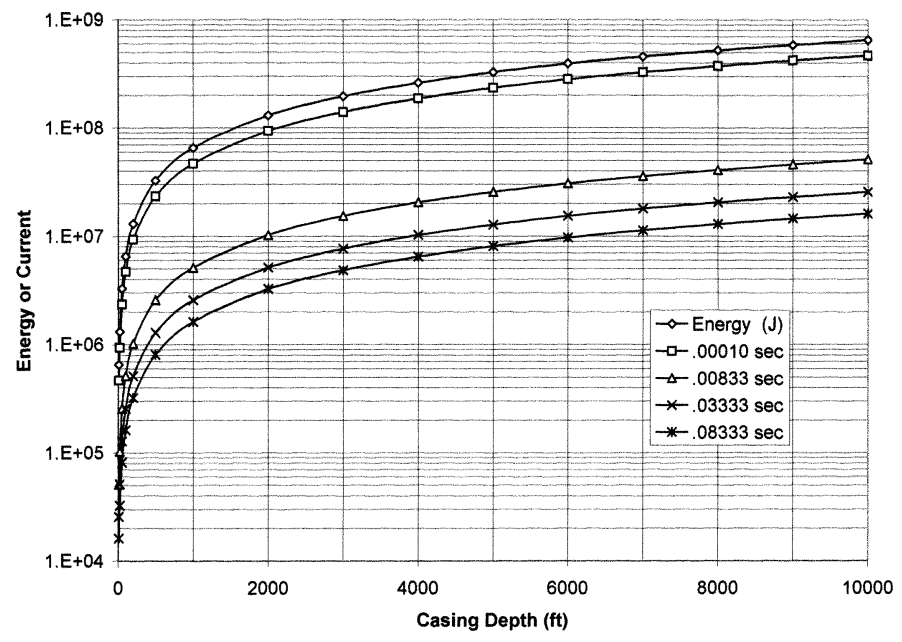

Fig. 3. Energy and current capacity for various depths and times.

this temperature range, so an average value of $2000 \Omega \cdot \mathrm{cm}$ was assumed.

From these parameters the energy put into the 1/8-in concrete sleeve surrounding the rod could be determined. After calculating the resistance of this concrete sleeve, a current-squaredtime value was calculated. Then by inserting appropriate typical times for a lightning stroke $(0.0001 \mathrm{~s})$, clearing time for a current-limiting fuse $(0.00833 \mathrm{~s})$, clearing time for a low-voltage circuit breaker $(0.0333 \mathrm{~s})$ and clearing time for a high-voltage circuit breaker $(0.0833 \mathrm{~s})$, the corresponding currents were resolved.

Similar calculations for the surface casing using identical times and the same assumptions are shown in Fig. 3. Actually, the casing would be bare below $1000 \mathrm{ft}$ and able to handle even higher energies and currents. Because no concrete damage was observed in the encased rod tests, it seems highly unlikely that any damage could ever occur to the concrete around a well casing. With a well casing much longer and many times larger in diameter than a lightning rod, the current/time capability is also many times larger. The currents calculated are far in excess of even the most improbable current values for lightning or protective device clearing.

\section{GROUND WIRES AND CONNECTIONS}

Wires have resistance, internal inductance, and external inductance. For transient voltages it could be reasoned that skin effect would be a problem because of the high frequency harmonics involved. To test this theory the authors impulse tested two 100-ft lengths of \#2 AWG wire. One was common stranded construction but the other was Litz wire. Basically the predominant parameter was the external inductance as both types of wire produced the same result. Resistance and internal inductance were reasoned to have only minor effects. External inductance is generally taken as $0.5 \mu \mathrm{H} / \mathrm{ft}$. The conclusions drawn from this were that any length of ground wire detracts from the effectiveness of surge suppression, ground wires should be kept as short as possible and ground wires can be modeled as inductors.

For oil field usage \#2 AWG stranded insulated copper wire is far superior to solid, bare \#6 copper, the minimum National Electrical Code (NEC) requirement. The added mechanical 
strength helps to reduce inadvertent breakage due to vehicles or roaming cattle. Stranding also improves flexibility and lessens the occurrence of breakage.

Bare copper wire can be corroded away in just a few years if there are even moderately high levels of $\mathrm{H}_{2} \mathrm{~S}$ in the oil field. A \#6 quickly becomes a \#10, then a \#14, etc. Insulation greatly inhibits this kind of corrosion. It also decreases the possibility of side flash during lightning storms when bare wires are just lying on the ground.

Ground clamps are widely used to connect ground wires to the wellhead piping and thus the casing, even though other types of connections are more reliable and have higher current capacity. Exothermal welding or ground bonding (brand names Thermoweld, Cadweld, etc.) of ground wires to ground terminals is more desirable. However, exothermal welding to a well casing has both proponents and opponents.

Opponents cite the possibility of fracture where the welding is done. The heating is very localized, quenched by the surrounding steel mass and forms a brittle microstructure. Since a post-weld heat treat is not practical, stresses in the casing cannot be relieved. This is particularly true when the casing steel has high carbon $(\mathrm{C})$ and molybdenum $(\mathrm{Mn})$ content such that:

$$
\mathrm{C}+\frac{\mathrm{Mn}}{6}>0.42 \% \text {. }
$$

Oil producing companies concerned about this possibility prohibit ground bond welding to their well casings.

Proponents of ground bonding, including the weld material suppliers themselves, allude to the successful widespread use for bonding cathodic protection conductors to gas transportation pipelines operating at very high pressures. Steel thickness must the greater than one-quarter inch to avoid any possible gas ignition problems. Proponents cite the high current-carrying capacity and reliability of ground bonding. Until these two sides can come to an agreement, the question of ground connections will remain a judgment call.

Ground wire burial has its proponents and opponents also. Proponents believe this eliminates the possibility of breakage, as mentioned above, and the inadvertent failure to reconnect the grounding after equipment change out. Opponents are concerned about breakage due to digging and think that a wire lying on the surface is easier to check. However, there are safety issues with a wire on the surface. Again, it is a judgment call.

The connection of ESP equipment should not be a judgment call. With the absolute lowest ground resistance, the wellhead should be the primary ground. Further, the wellhead is in direct electrical contact with the motor housing, so any TVSS must be connected as closely as possible to the wellhead in order to be maximally effective. Power system grounds, chemical grounds, ground grids and rods have increasingly higher ground resistance. The central question is always what ESP equipment should be connected to which ground and what type of system grounding should be used?

Five general grounding connections are evaluate below. These include:

- single in-line ground wire;

- lightning arresters connected to the transformer secondary;
- grounding to the power system;

- corner grounded delta-connected windings;

- separate ground wires from the wellhead to the power system and from the wellhead to the ESP equipment.

When a single ground wire connects the power system ground (pole butt wrap) to the wellhead, Fig. 4(a), the entire surge currents from both the primary lightning arresters and the TVSS are carried by the same wire. Therefore, the initial surge voltage at the ESP motor terminals is not just the TVSS clamping voltage but also the lead inductance times the rate of change in both lightning arrester and TVSS current. Since this latter voltage can be extremely large, the ESP voltage is very poorly clamped and surge protection is most ineffective. In many arid oil fields $\mathrm{Rj}$, Rs, and $\mathrm{Rb}$ are high and can be neglected

Using lightning arresters on both the primary and secondary sides of the transformer, as shown in Fig. 4(b), creates an even greater hazard. The voltage across the pole ground wire can be quite high, particularly with rapidly changing current. In arid regions the butt wrap ground resistance is often high also. This being the case and zinc oxide being a bilateral element, surge current through the primary lightning arrester passes through the secondary arrester in an opposite polarity, and this can put a very high voltage on the ESP, equal to the primary-side lightning voltage minus the clamping voltages of the two arresters.

Grounding only to the power system with no connection to the wellhead, as seen in Fig. 4(c), raises the ESP voltage by the sum of TVSS and arrester currents times the pole wire ground resistance plus the TVSS clamping voltage and the inductive voltage across the switchboard to power system ground wire. $\mathrm{Rj}$ and $\mathrm{Rs}$ are neglected as above. However, the pole (butt wrap) ground resistance can be quite large also, and this greatly jeopardizes ESP protection.

Most rural electric cooperatives follow the grounding recommendations of their central organization and install corner grounds on their delta connected $480-\mathrm{V}$ service, similar to Fig. 4(d). This does provide somewhat better lightning protection for their transformers, as discussed above under solidly grounded systems. However, this connection has absolutely awful implications for the electronics in variable-speed drives and any electrical insulation. The grounded phase is subjected to the full surge voltage at the base of the lightning arresters, which equals the surge current times the butt wrap ground resistance plus the rate of change in surge current times the pole wire lead inductance.

The corner grounded delta may save transformers and minimize power theft, but for oil field applications and particularly power electronics, the cost of failed oil field equipment far exceeds the value of a few transformers. Transformer transient behavior and protection is covered in the next section. Power theft should not be a problem in the oil field either. It makes no sense to apply general rural commercial and residential considerations to ESP operations.

Another concern with the corner-grounded delta is the creation of rather large circulating currents in the earth. They can produce large voltage gradients across the earth, and over the years several cases of cattle electrocution have been documented. 


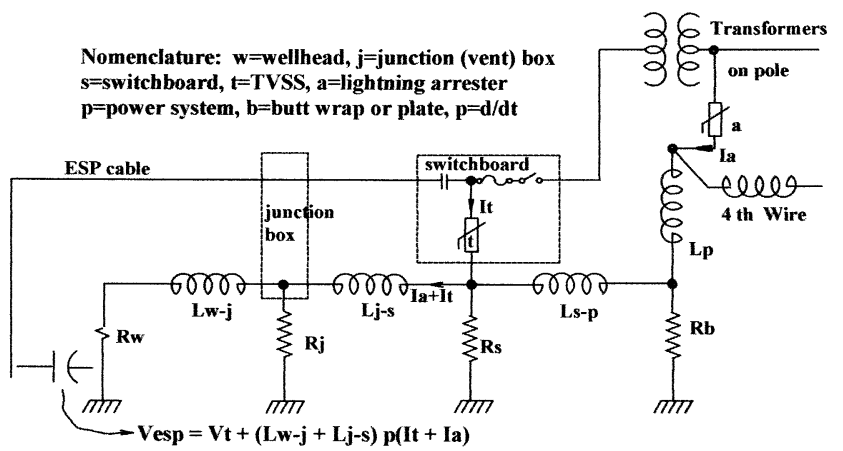

(a)

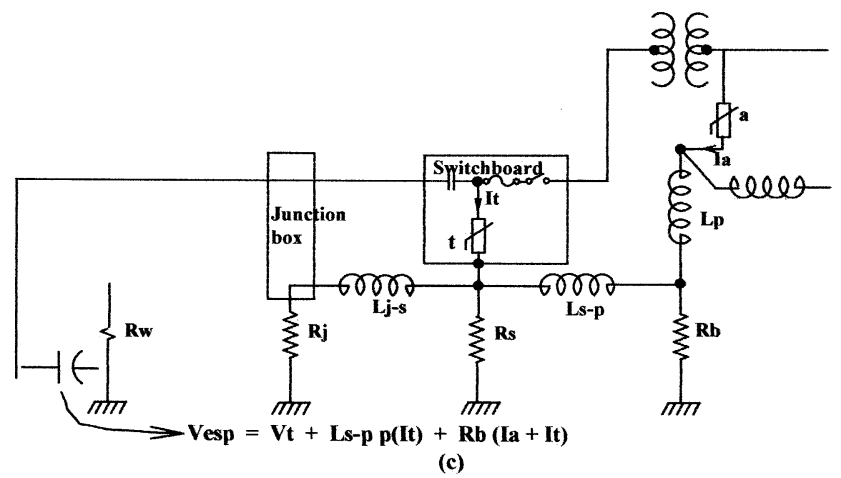

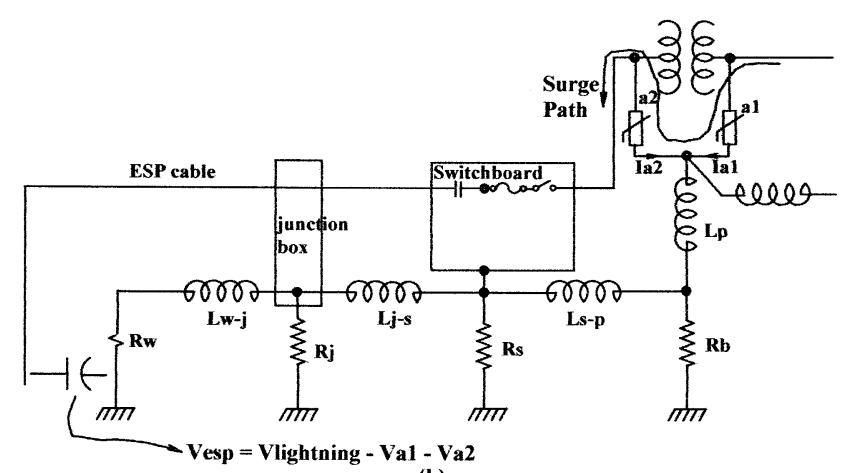

(b)

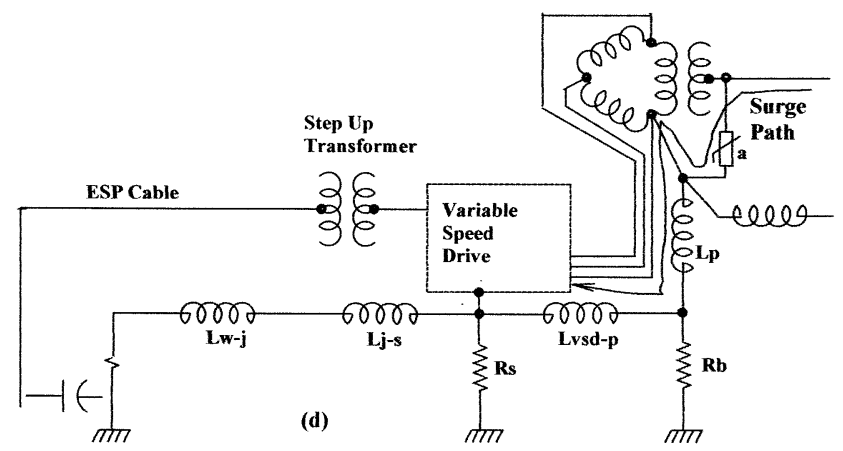

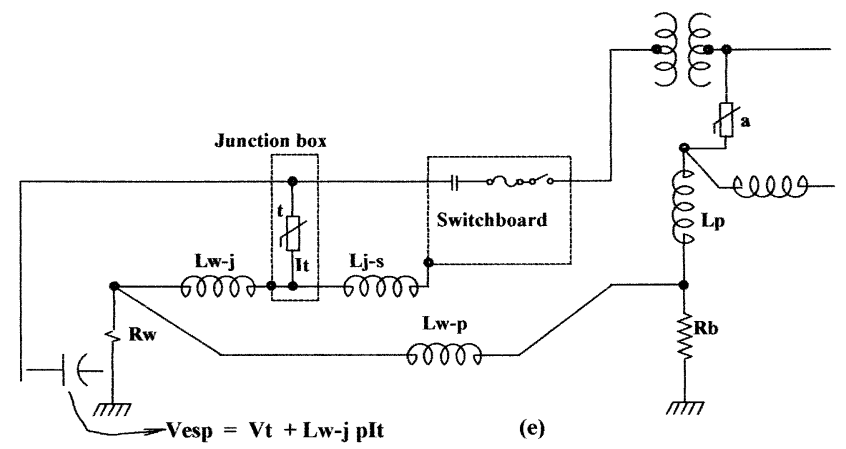

Fig. 4. Ground connections. (a) Common ground. (b) Secondary lightning arresters. (c) Power system grounding. (d) Corner-grounded delta. (e) Separate ground wires.

The separate ground wires approach [7] espoused by many major oil companies is illustrated in Fig. 4(e). Here. the lightning surge on the power system has no effect on the ESP system, except for the portion which passes through the transformer. This is discussed in a following section. Connection of the power system ground to the wellhead with a long, inductive wire may not improve transformer protection significantly, but it at least does improve power system grounding. Most importantly, with a separate power system connection large lightning surges on the high-voltage side of the transformers are diverted away from the ESP.

With a second separate ground wire to the ESP components, the ESP voltage equals the TVSS clamping voltage plus the inductive voltage drop on the short ground wire connecting to the wellhead. Since this surge is far less than the power system surge and the second wire has much less inductance, the rate of current change through the second wire produces a much smaller voltage. This is the preferred connection.

\section{TRANSFORMER TRANSIENT BEHAVIOR}

Power transformers are designed specifically for operation at a low, constant frequency, generally 50 - or $60-\mathrm{Hz}$ for ESP installations. Efficiency, temperature rise and insulation integrity are the most important items in the design. High frequency or impulse performance is seldom the most important design consideration.

Transformers do experience lightning and switching surges, and a given transformer reacts to these voltage waveforms in rather definite and repeatable ways. The traditional transformer equivalent circuit must be augmented with additional circuit elements, in particular an interwinding capacitance. A precise theoretical treatment is far beyond the scope of this paper, but detailed analyzes of transformer-transient behavior are readily available, [11]. Still, a general understanding does not require one to endure all these excruciating details.

Two effects take place in the transformer, magnetic and electric coupling between primary and secondary windings. Some 
years ago a major ESP transformer manufacturer was trying to introduce a product line with an electrostatic shield between the windings that would virtually eliminate the electric coupling. To evaluate the product impulse tests were performed on identical transformers, one with the shield and one without [12]. The shield did indeed greatly reduce the electric coupling, but the magnetic coupling persisted. Their solution was to filter secondary voltages due to the magnetic coupling.

Test results on the unshielded transformer were also enlightening. Line-to-line and line-to-ground voltages were measured to determine the extent of magnetic and electric coupling, respectively. In both, the secondary impulse voltages measured were about one-third of the applied impulses.

It was argued in the Introduction that the ESP motor, being primarily inductive, produced $a+1$ reflection coefficient at the end of the ESP cable. Even with impulse voltages, losses in a transformer can still be largely ignored, and this implies that the transformer response must be nearly equal to the applied impulse voltage. Since one-third of the voltage is transmitted through the transformer, two-thirds must be reflected.

These results have rather interesting repercussions for ESP surge behavior. Lightning arresters on the transformer primary will experience a peak voltage two-thirds higher than the impinging impulse. Pulses of even small amplitude can exceed the lightning arrester threshold. Electric cooperatives recommend lightning arrester connection directly to transformer cases to provide the best winding-to-case protection against this phenomenon.

On the transformer secondary the impulse going through the ESP components, (switchboard, junction box and downhole) has already been reduced from the peak value of the incident wave. The peak current rating of the TVSS can be somewhat less than the arresters and still perform very well. By insuring that primary and secondary surges take separate paths to ground, ESP protection can be significantly improved.

Tests on the shielded transformer showed that a reduction in interwinding capacitance did greatly diminish the surge coupled through the transformer. Although the engineering was sound, the shielded winding concept was not a commercial success. As with the TVSS, proper installation and grounding played an important role. Due to ground wire inductance and ground resistance it was almost impossible to keep the shield near ground potential during a lightning event. So, rather than being a panacea, the shielded transformer became just another possible tool for minimizing lightning damage if it was installed properly.

\section{OILFIELD POWER Distribution}

Four-wire distribution provides far superior lightning protection in the oilfield. With a fourth wire tied into the ground wire on every pole, any surge has multiple paths to ground. Another viewpoint would consider multiple pole grounds in parallel effectively forming a much lower total ground resistance. The fourth wire should be connected to the substation system ground so that the primary neutral point on a wye-wye transformer bank can be properly grounded. When the fourth wire is an overhead neutral, the phase wires are additionally shielded from direct lightning strikes.

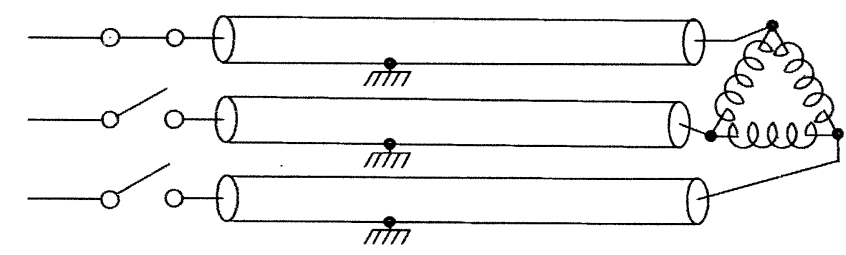

(a)

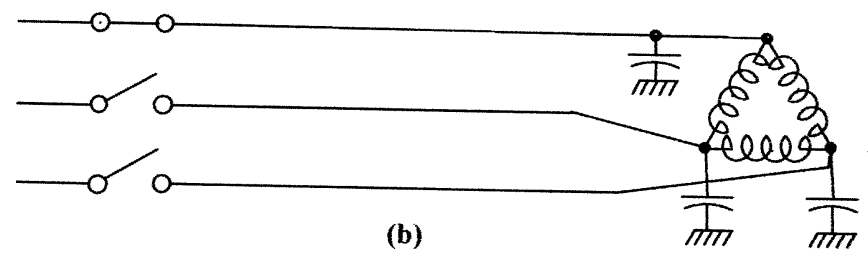

Fig. 5. Ferroresonance in power distribution. (a) Power cable feeding a deltaconnected winding. (b) Equivalent electrical circuit.

An underbuilt neutral does not offer this shielding protection. Lightning energy must be transferred to the fourth wire by arresters, and the NEC only requires arresters at poles having attached equipment. In the oilfield, it is not uncommon to have distribution lines with 20 or more poles and no attached equipment. Prudence would dictate additional banks of lightning arresters, as frequently as every one-third mile [14].

In many ways, an underbuilt neutral is the easiest way to safely upgrade a three-wire system without disrupting oil production. A fourth wire keeps ground resistance low thereby improving the performance of protective equipment and ensuring that lightning arresters do not simply short out when they fail.

A percentage of oilfield distribution is still three-wire construction because it was the least expensive to install when lines were first built under the Rural Electrification Act (REA). However, the lightning damage to electrical equipment has long since cost more than any initial savings. With grounding only possible at a well site, it is very understandable that ESP equipment failure is not uncommon. This is especially true for equipment connected at the end of a distribution feeder where a traveling-wave impulse can nearly double in magnitude. Three-wire systems make it impossible to ground the primary neutral of a wye-wye transformer bank, and the resulting phase-to-ground voltages are peaked and nonsinusoidal, creating additional equipment damage. For an oil company a good investment with a short payback is the conversion of any three-wire system into a four-wire system.

\section{FERRORESONANCE}

Three-wire power systems operating at high voltages can produce ferroresonance, and one classic example is the cable-fed delta-connected windings illustrated in Fig. 5(a) [11]. Two of the three disconnects are open, but the third is exciting two, series-resonant circuits to ground [Fig. 5(b)]. Capacitance is supplied by the feed cables. At high voltages, the inductance is necessarily large and can resonate with the capacitance at power frequencies, 50 or $60 \mathrm{~Hz}$.

With the capacitor and inductor in series their respective voltages are $180^{\circ}$ out of phase, and the excitation voltage only needs to supply the difference. There is no restriction on inductor voltage, and the transformer magnetizing inductance 
can be driven far into the nonlinear, saturation region. This produces very large and peaked voltages and currents that regularly damage electrical equipment. The fundamental frequency is still the power frequency, but because of the irregular waveshapes, numerous harmonics are generated.

As more and more REA lines are upgraded from 12.5 to $25 \mathrm{kV}$ to supply increased loads, ferroresonance is becoming a larger problem. Wye-connected grounded-neutral windings restrict the transformer voltage and thus eliminate the problem; however, the REAs are concerned about currents on the fourth wire. It is common practice to supply a pole-mounted disconnect between the transformer neutral and the fourth wire. To avoid ferroresonance this disconnect must be closed when the other disconnects are being opened or closed to de-energize or energize a transformer bank, respectively. When all disconnects are closed the fourth disconnect is normally opened, if the transformer secondaries are delta connected thereby supplying third harmonic magnetizing current. There is one other problem with opening this grounding connection. With no connection to the fourth wire, the effectiveness of lightning arresters is compromised.

Several oil fields in the Middle East use three-wire power systems because grounding is such a problem in that arid terrain. 33- and 34.5-kV supplies are common due to the distances involved, and most transformers have delta connected primary windings fed through several hundred meters of power cable. One positive is that the delta connected primary supplies thirdharmonic magnetizing current so the tap-changing secondary windings can be connected either wye or delta, depending on the desired voltage.

However, this is a perfect prescription for ferroresonance, as demonstrated above. The high voltage means the transformer inductance must also be high, making power frequency resonance that much easier. Disconnect switches are three phase and pole mounted. If all three-phases can be opened or closed at the same instant, there would be little problem. However, at $33 \mathrm{kV}$ the disconnects are quite large, and simultaneous operation of all three phases is quite unlikely.

\section{CATHOdic PROTECTION}

The question of well-casing cathodic protection is extremely important to ESP grounding, because in many instances cathodic protection is cited as the reason why the wellhead can not be used as ground. This is the central issue addressed in this section.

The need for cathodic protection of tank batteries, production pipelines and other surface equipment can be determined from a soil resistivity test. Low soil resistivity implies high rates of corrosion whereas high resistivity indicates minimal corrosion. No cross-country pipelines can be operated without cathodic protection as required by the U.S. Department of Transportation[13].

It is almost universally accepted that a steel structure (pipeline) under cathodic protection is fully protected if the potential is a least 0.85 -volt negative, referred to a standard copper-saturated copper sulfate electrode placed in the electrolyte immediately adjacent to the metal surface (on the soil above the pipeline). The entire structure is fully protected, of course, only if this criterion is met at every point on the surface.
Many techniques and measurements have been developed to evaluate the effectiveness of cathodic protection on pipelines. Some of these are pipe-to-soil potential, instant off potential, IR drop, dc voltage gradients and on/off surveys. These measurements have been refined to the point that holidays in a pipeline coating can be located within one foot, greatly reducing the digging required.

Unfortunately similar measurements on a well casing are simply impossible due to the depth and related inaccessibility. Today, the application of cathodic protection is mainly concentrated in fields with a history of known casing corrosion problems and in predominantly gas wells. Internal corrosion is largely controlled by chemicals injected into the well, but these have no effect on exterior casing corrosion. The design and placement of anode beds around a wellhead can rectify this problem, as has been demonstrated by over 40 years of experience. An insulating flange should electrically separate the wellhead and casing from the production pipeline.

However, if cathodic protection is applied to the well casing, the casing cannot be connected directly to the electrical ground system. This additional wire will drain off the cathodic current to other ground structures, e.g., rods, grids, etc., and casing protection will be reduced. Either the cathodic system or the electrical grounding system will be compromised producing increased casing corrosion or greater susceptibility to lightning damage, respectively.

Several tradeoffs are possible on the electrical side. Connecting to the wellhead through a low-voltage clamping device, e.g., an MOV, would limit the maximum voltage between the wellhead and the ESP ground. Since an MOV has very high resistance at low voltage, a parallel resistor of $20 \Omega$ or less would be necessary to satisfy NEC requirements. The cathodic system would be subjected to a very minimal and acceptable degradation.

Another possibility is the design of an electrical ground grid and appropriate bonding [15] totally avoiding any grounding to the wellhead. It was noted earlier that cathodic protection is necessary most when soil resistivity is low, and low soil resistivity produces low ground resistance. The ground grid would be quite effective.

\section{CONCLUSION}

From calculations and measurements, it was demonstrated that the wellhead is a superb ground with very low resistance and exceptional current carrying capability. Experience over many years further confirms this. An oil well is essentially a ground rod thousands of feet long. Many ground wire connection schemes have been used over the years, but many of these actually make lightning damage worse. Today, it is conceded that the best scheme is separate ground wires to the wellhead from the power system and from the ESP components. This connection scheme used with a TVSS grounding system solves many of the failure on startup, arcing fault and residual charge problems experienced. Four-wire distribution systems provide superior performance during thunderstorms and power disturbances. Ferroresonance can be avoided if the proper transformers are selected initially and are grounded properly at installation. Finally, cathodic protection and wellhead grounding can only coexist if additional circuit elements are introduced into the ground lead. 


\section{REFERENCES}

[1] T. R. Brinner, J. H. Bulmer, and D. W. Kelly, "Lightning protection for submergible oilwell pumps," IEEE Trans. Ind. Applicat., vol. IA-22, pp. 1133-1141, Nov./Dec. 1986.

[2] T. R. Brinner and K. R. Packard, "Methods to reduce electrical stress in variable speed drive applications," presented at the Society of Petroleum Engineers Electric Submersible Pump Workshop, Houston, TX, Apr. 1998.

[3] T. R. Brinner, "Voltage and cable impedance unbalance in submergible oil well pumps," IEEE Trans. Ind. Applicat., vol. IA-20, pp. 97-104, Jan./Feb. 1984.

[4] D. Beeman, Ed., Industrial Power Systems Handbook. New York: McGraw-Hill, 1955.

[5] C. C. Ku and R. Liepins, Electrical Properties of Polymers. New York: Hanser (Macmillan), 1987.

[6] F. Wenner, "Method of measuring earth resistivity-Report 258," Bull. Bureau Standards, vol. 12, no. 3, Oct. 11, 1915.

[7] M. O. Durham and R. A. Durham, "Lightning, grounding and protection for control systems," IEEE Trans. Ind. Applicat., vol. 31, pp. 45-54, Jan./Feb. 1995.

[8] H. G. Ufer, "Investigation and testing of footing-type grounding electrodes for electrical installations," IEEE Trans. Power App. Syst., vol. PAS-83, pp. 1042-1048, Oct. 1964.

[9] M. D. Conroy and P. G. Richard, "Deep earth grounding vs shallow earth grounding," in Proc. Power Quality Conf., Irvine, CA, Oct. 1993, pp. 837-846.

[10] E. J. Fagan and R. H. Lee, "The use of concrete-enclosed reinforcing rods as grounding electrodes," IEEE Trans. Ind. Gen. Appl., vol. IGA-6, pp. 337-348, July/Aug. 1970.

[11] A. Greenwood, Electrical Transients in Power Systems. New York: Wiley, 1991.

[12] "Filtered and shielded transformers," Southwest Electric Co., Oklahoma City, OK, Internal Rep., Aug. 1988.

[13] M. E. Parker and E. G. Peattie, Pipe Line Corrosion and Cathodic Protection. Houston, TX: Gulf, 1984, p. 27.

[14] R. A. Durham and M. O. Durham, "Industrial design application for power distribution over extra-long distances," in Proc. IEEE PCIC, Sept. 2001, pp. 217-224.

[15] — - "Corrosion impact of cathodic protection on surrounding structures," in Proc. IEEE PCIC, Sept. 2003, pp. 303-309.

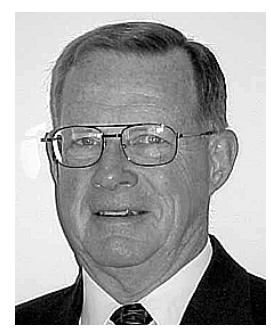

Thomas R. Brinner (M'75) received the B.S. degree from Washington University, St. Louis, MO, in 1963, the M.S. degree from Syracuse University, Syracuse, NY, in 1969, and the D.Sc. degree from The Ohio State University, Columbus, in 1973, all in electrical engineering.

Upon graduation in 1963, he joined IBM Corporation, Endicott, NY, as an Electronics Design Engineer. In 1973, he was associated with the General Electric Transportation Technology Center, Erie, PA, designing high-power electronics for subways. From 1976 to 1981, he was an Assistant Professor of Electrical Engineering at the University of Arkansas, Fayetteville. In 1981, he was Manager of Electrical Engineering at the TRW Reda Pump Division, Bartlesville, OK, and in 1990 Manager of Submersible Design at Franklin Electric, Bluffton, IN. Since 1995, he has been with PM\&D Engineering, Inc., Broken Arrow, OK, specializing in lightning protection of oil field equipment and surge suppressor design.

Dr. Brinner is a Past Chairman of the Ozark Section of the IEEE and is a Registered Professional Engineer in the State of Ohio.

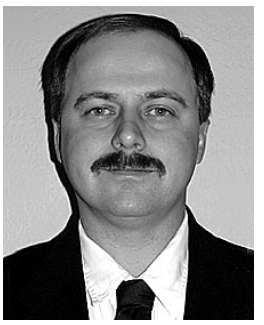

Jeremy D. Atkins received the B.S.E.E. degree, specializing in electric power systems, from New Mexico State University, Las Cruces, in 1999.

Upon graduation from high school, he joined Deans, Inc., Artesia, NM, as an Electrical Apprentice and continued with the company throughout his educational career. He has been a Staff Engineer with Deans since receipt of the B.S.E.E. degree. His job responsibilities include power system management, drive systems, and facilities control and protection. in the State of New Mexico.

$\mathrm{Mr}$. Atkins is a journeyman and contractor licensed

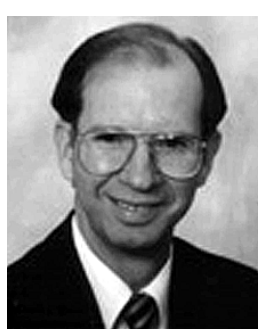

Marcus O. Durham (M'76-SM'82-F'93) received the B.S. degree in electrical engineering from Louisiana Tech University, Ruston, the M.E. degree in engineering systems from the University of Tulsa, Tulsa, OK, and the Ph.D. degree in electrical engineering from Oklahoma State University, Stillwater.

$\mathrm{He}$ is the Principal Engineer of THEWAY Corporation, Tulsa, OK. He is also a Professor at the University of Tulsa and President of Advanced Business Technology, Inc., an entrepreneurial firm in the e-commerce arena.

Dr. Durham is a Registered Professional Engineer in the States of Oklahoma and Louisiana, a state-licensed electrical contractor, and an FCC-licensed radiotelephone engineer. Professional recognition includes Diplomate of American College of Forensic Examiners, Member of the Society of Petroleum Engineers, and Task Group Member of the American Petroleum Institute. He has been awarded the IEEE Richard Harold Kaufmann Medal "for development of theory and practice in the application of power systems in hostile environments." He was recognized with three IEEE Awards for his Standards development work. He has been awarded numerous times for the over 100 technical papers he has authored. He is acclaimed in Who's Who of American Teachers, National Registry of Who's Who, Who's Who of the Petroleum and Chemical Industry of the IEEE, Who's Who in Executives and Professionals, Who's Who Registry of Business Leaders, Congressional Businessman of the Year, and Presidential Committee Medal of Honor. Honorary recognition includes Phi Kappa Phi, Tau Beta Pi, and Eta Kappa Nu. 